\title{
DETERMINATION OF AVAILABLE TRANSFER CAPABILITY (ATC) IN A COMPETITIVE ELECTRICITY MARKET USING NIGERIAN 3-BUS AND 14-BUS POWER NETWORK AS CASE STUDY
}

\author{
E. Omorogiuwa ${ }^{1, *}$ and E. Harrisson ${ }^{2}$ \\ 1,2, DePt. OF Electrical \& Electronic ENGINEERING, UniVERSITY OF PORT HARCOURT, RivERS STATE. NiGERIA \\ E-mail addresses :1 oomorogiuwa@yahoo.com, 2enarrison4jesus@yahoo.com
}

\begin{abstract}
In the deregulated power system, competition arises in generation and distribution but the transmission corridor remains the same for transferring power. Every operator wants to maximize profit, as such the number of transaction increases. This may cause congestion in transmission network. To avoid this, every operator should know the value of available transfer capability (ATC) before every transaction. Determination of ATC is a complex task which has to be done at periodic intervals for each source and sink pairs. Though there are many methods available to assess ATC, the most accurate method is repeated power flow using newton raphson (RPFNR). In this research work, RPFNR approach was applied on both 3-bus and 14 bus network by modeling and simulation using Power World Simulator (PWS). ATC between nodes and areas for both networks were determined. The error difference between ATC obtained from both procedures was negligible. A 14-bus system was further modeled, and ATC between nodes and areas were determined.
\end{abstract}

Keywords: ATC, RPFNR, PWS, bus, grid, deregulated, contingency

\section{INTRODUCTION}

Around the globe, the once bundled and integrated structures in electric power system are changing to competitive, privatized and deregulated frameworks. In the current electricity markets, transmission grids are going to function very close to their thermal and voltage limits. Therefore it is imperative to know the amount of extra power that can be transferred from one point to another or from generators to loads in the power system at this moment and in future from the view point of system operation and planning. Additionally, Independent Power Producers (IPPs) and customers have access to transmission network; hence it becomes very crucial to calculate available transfer capability (ATC) as simply and efficiently as possible [1]. ATC is the measure of transfer capability available in transmission network for further commercial activity over and above already committed uses [2]. Mathematically,

$$
A T C=T T C-T R M-C R M
$$

Where: ATC-Available Transfer Capability; TTC - Total Transfer Capability; TRM-Transmission Reliability Margin; ETC-Existing Transmission Commitments; CBM -Capability Benefit Margin [3].Efficient determination of ATC helps to improve the security of transmission network as it helps to automatically regulate the network. It helps in maximizing the cost of wheeling power through the network because only the required power is transmitted per time thereby bringing economic efficiencies to power producers. When the system is overloaded or congested, the distribution stations are required to drop loads and when the load drops beyond that which is appropriate they are required to pick up loads, this back and forth activity affects the frequency and overall stability of the system but the knowledge of ATC brings accuracy.

\subsection{Competitive Electricity Market}

Transmission network is a vital mechanism in competitive electricity markets as such electricity market is defined as a restructured system in which power producers (Suppliers) compete with each other to provide the best possible service at lowest cost and high power quality in order to attract and retain customers. In a restructured power system, transmission network is where generators compete to supply large users and distribution companies.

\footnotetext{
* Corresponding author, tel: +234-805- 515- 0986
} 
With power sector deregulation, several independent power producers have evolved in the country thereby creating opportunity for competition. The development has also led to the increase in the amount of electric power generated in the country to about $4,405.60 \mathrm{MW}$ as at Jan 2015 [4]. With such competition in the market and corresponding increase in power been generated, accurate determination of ATC in transmission network becomes paramount. In a competitive environment, proper transmission pricing could meet revenue expectations, promote efficient operation of electricity markets and most importantly promote fairness and be practical. However, it is difficult to achieve efficient transmission pricing scheme that could fit all market structures in different locations [5]. Congestion may result in preventing new contracts, infeasibility in existing contracts, price spike in some regions and market power abuse. Though congestion exists in both bundled and unbundled power systems, it is very complex in deregulated power system due to its unbundled nature. To relieve congestion, cost free and non-cost free congestion management methods are accessible. Cost free methods do not include GENCO and DISCO i.e., economical matters are not involved and congestion is relieved technically by incorporating phase shifters, transformer taps, and Flexible AC Transmission Systems (FACTS) devices in the power system [6]. These challenges are due to the following:

$>$ Lack of adequate information on transmission pricing which affects power producers (suppliers) adversely.

$>$ The entire network is always subject to congestion and in the near future as competition increases in electricity market.

$>$ Lack of firm/flexible reservation of transmission services because ATC is not known

The aim of this paper is to determine ATC in a competitive electricity market. A part of the northern section of Nigeria $330 \mathrm{kV}$ grid network is used as a case study in determining ATC. For the purpose of this research, the available transfer capability shall be determined considering the voltage limit only.

The study objectives include:

$>$ To establish and provide adequate information for transmission pricing.

$>$ To adequately manage the problem of overloading and congestion as it arises in the near future.

$>$ To provide concrete information for power producers to know what amount of power to wheel and what amount to reserve at each point in time.
In 2012, [7] discussed an efficient method of determining ATC with and without flexible AC transmission systems (FACTS) devices. The findings result in development of a sensitivity based approach for obtaining ATC in a deregulated market having pool and bilateral dispatches. [1,7] proposed a method of determining ATC of transmission network using fuzzy logic based ATC evaluation which takes into consideration: sink bus load, neighboring bus injection, and loading index as input signal for the fuzzy system. The advantage of fuzzy logic is that it handles the dimensionality of a problem in an efficient manner and can capture uncertainties that are inherent in the system. Continuous power flow method for assessment of ATC which uses full AC power flow solution incorporating the effects of reactive power flow, voltage limit and voltage collapse as well as traditional line flow, thermal loading effects was proposed [9]. Since optimization approach with various control measures are not used, ATC obtained was conservative. [10] computed ATC for various transmissions using continuation power flow method on IEEE 14-bus test system and IEEE 24-bus reliability test system during normal and contingency cases considering line thermal limit and bus voltage limits. The ATC was found to differ under contingency case than normal condition. Discussion on a simple and an efficient method for determining ATC between two buses using repeated power flow method was effectively carried out [12]. The relevant equations involved in carrying out repeated power flow (RPF) are shown in equations (2) - (9). In order to determine the voltages and current in a particular bus (node) equation (2) is used. Equations (3) and (4) are used to determine the summation of active as well as reactive powers in a particular node or bus. In determining the diagonal matrix, equation (5) is applied. Equations (6a) and (6b) are used to determine active and reactive power at node or bus $\mathrm{L}$. The total transfer capacity as well as the available transfer capacity are determined by equations 8 and 9 respectively.

$$
\begin{gathered}
p_{V}-j Q_{v}=V_{v} I_{v} \\
P_{y}=\sum_{q-i}^{n} / V_{p} / V_{q} / Y_{p q} / \cos \left(\theta_{p q}-\delta_{p}-\delta_{q}\right) \\
Q_{v}=\sum_{q-i}^{n} / V_{p} / V_{q} / Y_{p q} / \\
\cos \left(\theta_{p q}-\delta_{p}-\delta_{q}\right) \\
\left(\begin{array}{c}
\Delta P \\
\Delta Q
\end{array}\right)=\left(\begin{array}{ll}
J 1 & J 2 \\
J 3 & J 4
\end{array}\right)\left(\begin{array}{c}
\Delta \delta \\
\Delta / V /
\end{array}\right)
\end{gathered}
$$

The diagonal elements J1, J2, J3 and J4 are found using

\section{LITERATURE REVIEW}




$$
\begin{gathered}
\frac{\delta P_{p}}{\delta Q_{p}}, \quad \frac{\delta P_{v}}{\delta / V_{p} /}, \quad \frac{\delta Q_{p}}{\delta Q_{p}}, \\
\frac{\delta Q_{v}}{\delta / V_{p} /} \text { respectively } \\
P_{L}=P_{p q}+P_{q v}=\left(V_{p}^{2}+V_{q}^{2}\right) G_{q p} \\
-2 V_{p} V_{q} \cos \left(\delta_{p}-\delta_{q}\right) \\
Q_{L}=Q_{p g}+Q_{q v} \\
=\left(V_{p}^{2}+V_{q}^{2}\right)\left(B_{q p}+B_{c}\right)\left(C_{q}^{c}\right) \\
+2 V_{p} V_{p} \cos \left(\delta_{p}-\delta_{q}\right) \\
T T C=\Sigma P_{L i}+P_{v s c l o a d} \\
A T C=T T C \Sigma P_{L T i}
\end{gathered}
$$

Where $\Sigma P_{L T i}$ is summation of real load at all buses, $P_{\text {Vsc,Load }}$ is maximum loading limit at sink bus and $\Sigma P_{L i}$ is the summation of base case real power loads at all buses except sink bus [11,13].

Repeated power flow using Broyden-Shamanski method was investigated [14]. This method eliminates the drawback of the Newton Raphson method (which requires very high computational time). The proposed approach was tested with a WSSC 9-bus, New England 39-bus and IEEE 144-bus tested system and the results were compared with the conventional RPF using Newton Raphson. At the end of the work, result showed that the computational time is far less than the conventional Newton Raphson method while maintaining accuracy.

The researcher [8] computed ATC using RPF method considering voltage profile. The suggested methodology was tested on IEEE 30-bus system. The effect of FACTs devices on ATC was studied and it was discovered that appropriate location of the devices on the network improves the value of ATC greatly. A new method of determining ATC of transmission network was proposed known as bender decomposition method [15]. The problem was developed as an optimization model putting into considerations all the contingency conditions and normal operating conditions of the system in details. The model is divided into two levels: slave and master levels. The slave level interacts with the master level until the process converges. Also discussed on assessment of ATC was carried out by [15] and divided the subject into two categories deterministic ATC and probabilistic ATC. ATC was calculated for IEEE 30 bus systems which took into account full AC load flow, linear optimization, thermal and voltage constraints. The results obtained from MATLAB programming were used to estimate the ATC. Proposal on ATC calculation using DC power flow model for both single and multiple transactions was made [16]. ATC is calculated for both intact and contingency cases. Two types of contingencies were considered (One line and contingency. Transfer capacity terms calculations and applications were investigated [17], while [18] computed ATC using optimal power flow method in a competitive electric market using thyristor controlled series compensators (TCSC). OPF was discovered to remove the congestion, i.e. overload by redistributing the power over other lines. However the disadvantage observed when using this method is that congestion affected zone prices in the entire networked system, whereas market participants will prefer to have one market price in reasonably large region. Implementation of a novel method known as Hybridized Continuous Repeated Power Flow (HCR-PF) to compute inter-area ATC was carried out $[19,22]$ and formulated a method based on computed ATC in evaluating the transmission efficiency by measuring the transfer efficiency of the transmission system in order to obtain ATC. The result showed that HCR-PF is a good alternative for ATC computation after due validation using IEEE 30-bus test network. [20] Initiated evolutionary algorithm to determine the value of ATC in an IEEE 24 RTS bus system. The result obtained was found to be well enhanced within a minimal period of execution. The effects of FACTS devices (TCSC and SVC precisely) on ATC was tested and it was seen to have improved the value of ATC. [18] employed AC power Transfer Distribution Factors (ACPTDF) in an IEEE 24-bus Reliability Test System in the determination of ATC. The results obtained were compared with the value of ATC in the network when TCSC is utilized and was realized that TCSC improved the ATC of the network. [20] evaluated the available Transfer capability of IEEE 30 bus systems by using the Evolutionary Genetic Algorithm and also incorporated matlab software for determining ATC between any bus in a deregulated power system. The simulation results showed the effectiveness of genetic algorithm method in calculating the value of ATC. [21] Calculated ATC values by selecting optimal leading factor, from the Differential Evolution Algorithm (DEA) which is used as an optimization foot on IEEE 24 bus Reliability Test System (RTS) and IEEE 118 bus system. The method established bilateral/multilateral towards load demand transaction based on the optimal generator selection and it's sharing.

\section{METHODOLOGY}

The method adopted for the research involves the following:

- Review of relevant literatures on ATC for a competitive electricity market

- Carry out RPF using Newton Raphson (NR).

- Establish and solve for a base case

Vol. 37, No. 3, July 2018 
- Select and solve for Transfer case

- Increase step size if Transfer is successful or decrease step size if unsuccessful

- Repeat procedure until minimum step is reached

- Model the same network in Power World Simulator (PWS) environment

- Compare results and obtain the difference error. A part of the northern section of Nigeria $330 \mathrm{kV}$ grid network is used as a case study in determining ATC. The 3-bus system considered is shown in Figure 3.1.

\subsection{Description of the Network}

Figure 1 shows a one line diagram of a section of Nigeria $330 \mathrm{kV}$ network and its transmission line parameters. It consists of Jebba, Kanji and Birnin-Kebbi and are made of slack, PV and PQ buses respectively. Figure 2 shows the simulation model obtained after carrying out RPF to determine ATC. Table 1 shows results obtained. This result was validated to ascertain the software/program accuracy by applying N-R algorithm to the same 3-bus network and the error difference is shown. Figure 3 describes the flow chart used for the study.

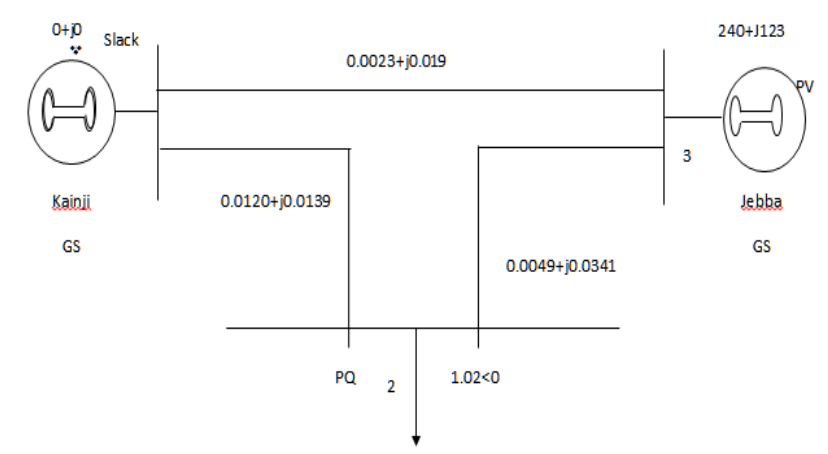

Figure: 1: One line Diagram of a section of Nigeria $330 \mathrm{kV}$ network

Table 1: Results obtained using N-R Algorithm

\begin{tabular}{llccc}
\hline From & To Bus & $\begin{array}{c}\text { ATC }(\mathrm{N}- \\
\text { R) }\end{array}$ & $\begin{array}{c}\text { ATC } \\
\text { (PWS })\end{array}$ & $\begin{array}{c}\text { Error } \\
\text { Difference }\end{array}$ \\
\hline Kainji & BirninKebbi & 269.05 & 269.03 & 0.02 \\
Kainji & Jebba & 109.04 & 108.98 & 0.03 \\
Jebba & BirninKebbi & -93.04 & -92.06 & 0.02 \\
\hline
\end{tabular}

\subsection{Simulation of 14-Bus Network under Normal Working Condition}

Having ascertained the accuracy of the PWS program for digital computation, it was then further extended to fourteen(14) bus network of the Nigeria $330 \mathrm{kV}$ power system as shown in Figure 4.It involves simulation of the network under normal working condition.

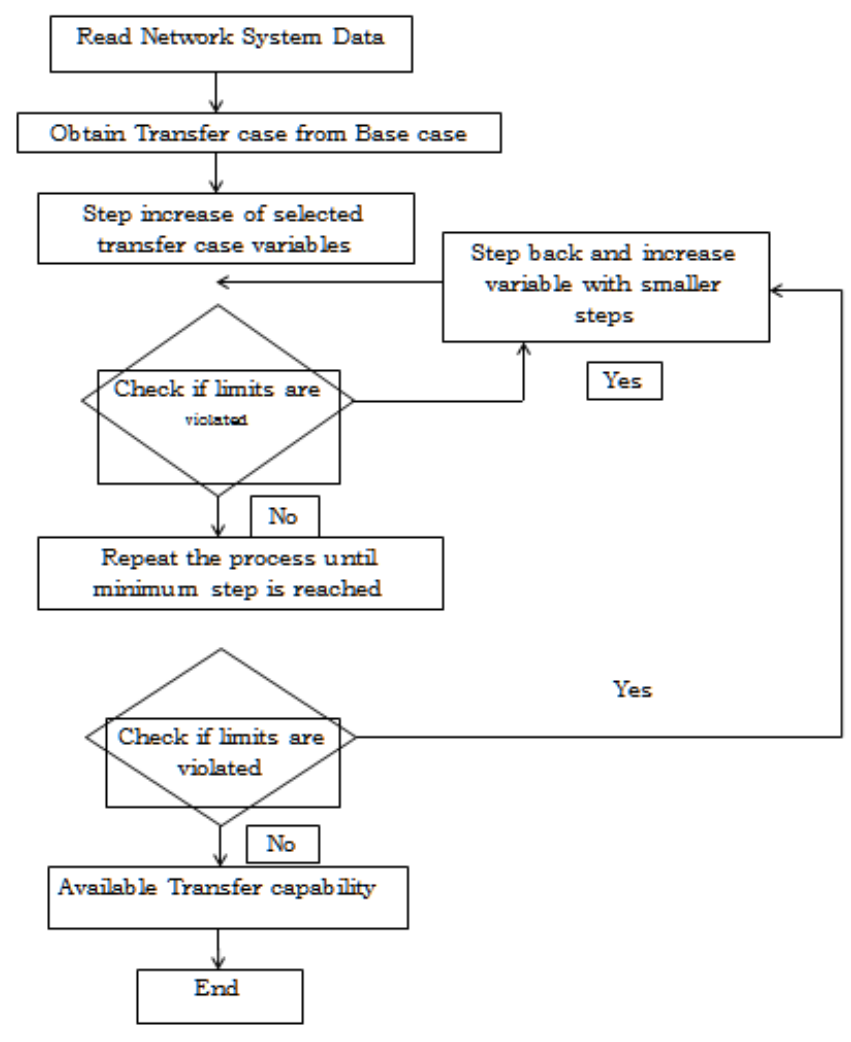

Fig. 2: Flow chart of RPFN-R

\subsection{Simulation of 14-Bus Network Considering Line Contingency}

The power network was subjected to line contingency and it was observed that the system reacted to sudden disturbances in the network. When the Kaduna - Kano line was opened, the bus and line parameters were seen to vary and consequently the ATC of the network. In the case of line contingency, the value of ATC in most lines were observed to have increased, the following was obtained. This is shown in Figure 5.

\subsection{Simulation of 14-Bus Network (Generator Contingency)}

In considering the effect of generator contingency, Jebba GS was removed from the network and the power flow as well as the ATC was determined. This is shown in Figure 6.

\section{RESULTS AND DISCUSSIONS}

Table 3 shows comparison of results obtained for ATC under three conditions:

\section{* Normal system operation \\ * Line contingency \\ * Generator contingency}

It was found that under normal working condition, the highest value of ATC was obtained to be 618.97MW and it was observed to flow from Shiroro-Kaduna while the least flow is $10.93 \mathrm{MW}$ and the flow is from Kainji TSJebba TS. 


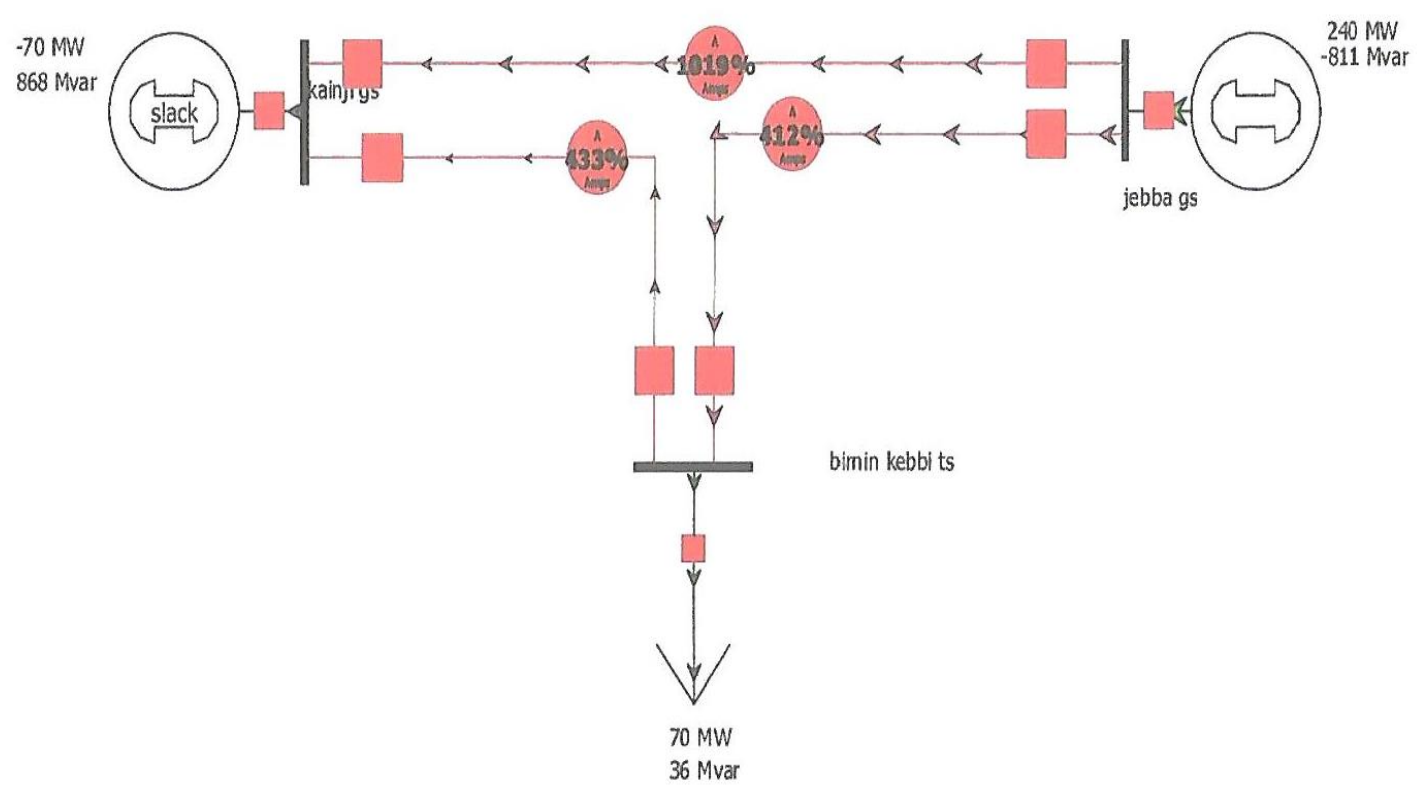

Figure 3: Model obtained using RPF algorithm

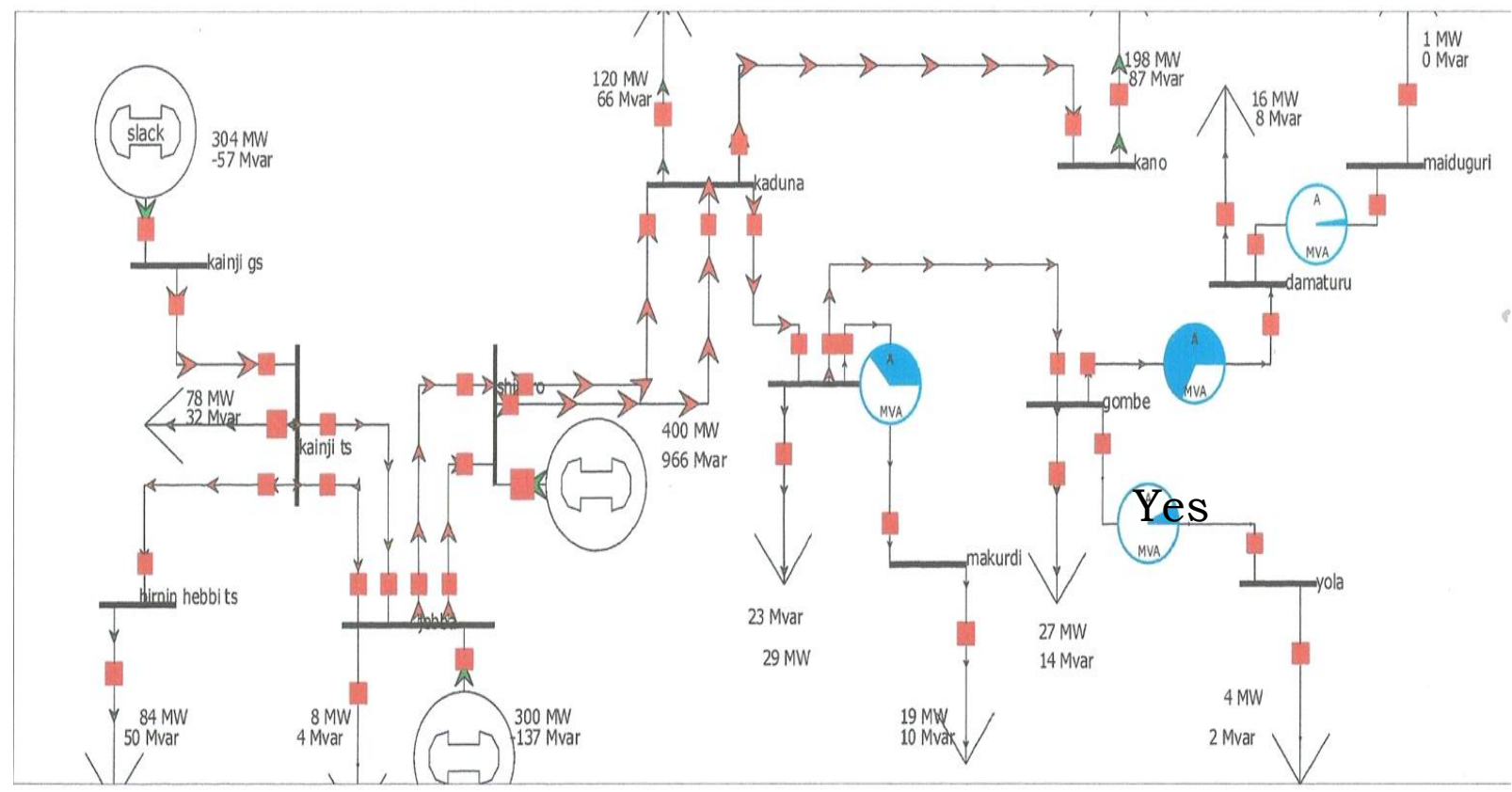

Figure 4: Simulated 14-bus network in a normal condition

While under line contingency, it was observed that the flow from Kaduna-Kano gave power of zero (i.e. the line was opened). The power network when subjected to line contingency, the system reacted to sudden disturbances at about 0.606 milliseconds. When the Kaduna - Kano line was opened, the bus and line parameters were seen to vary and consequently the ATC of the network. In the case of line contingency, the value of ATC in most lines were observed to have increased as shown in Figure 5. 


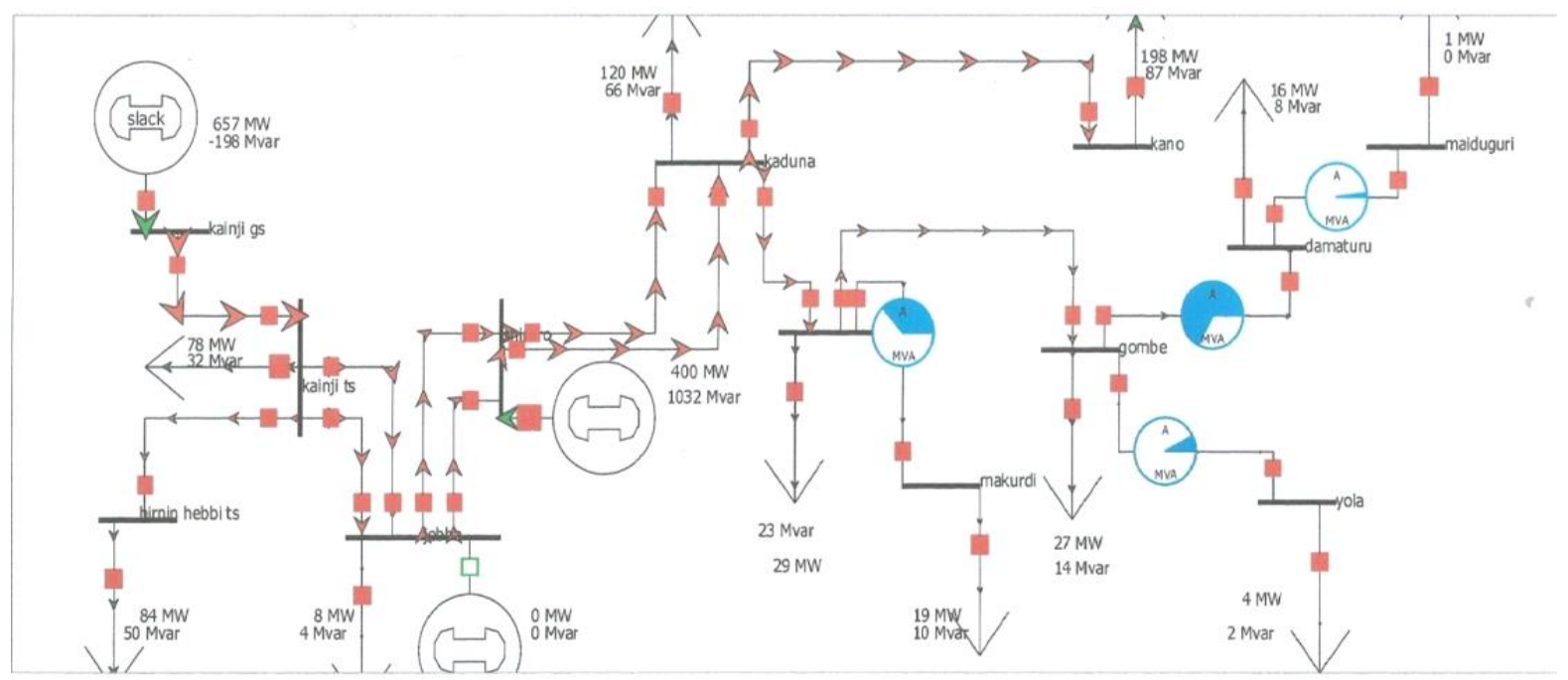

Fig. 5: Simulated 14-bus Network (Line Contingency

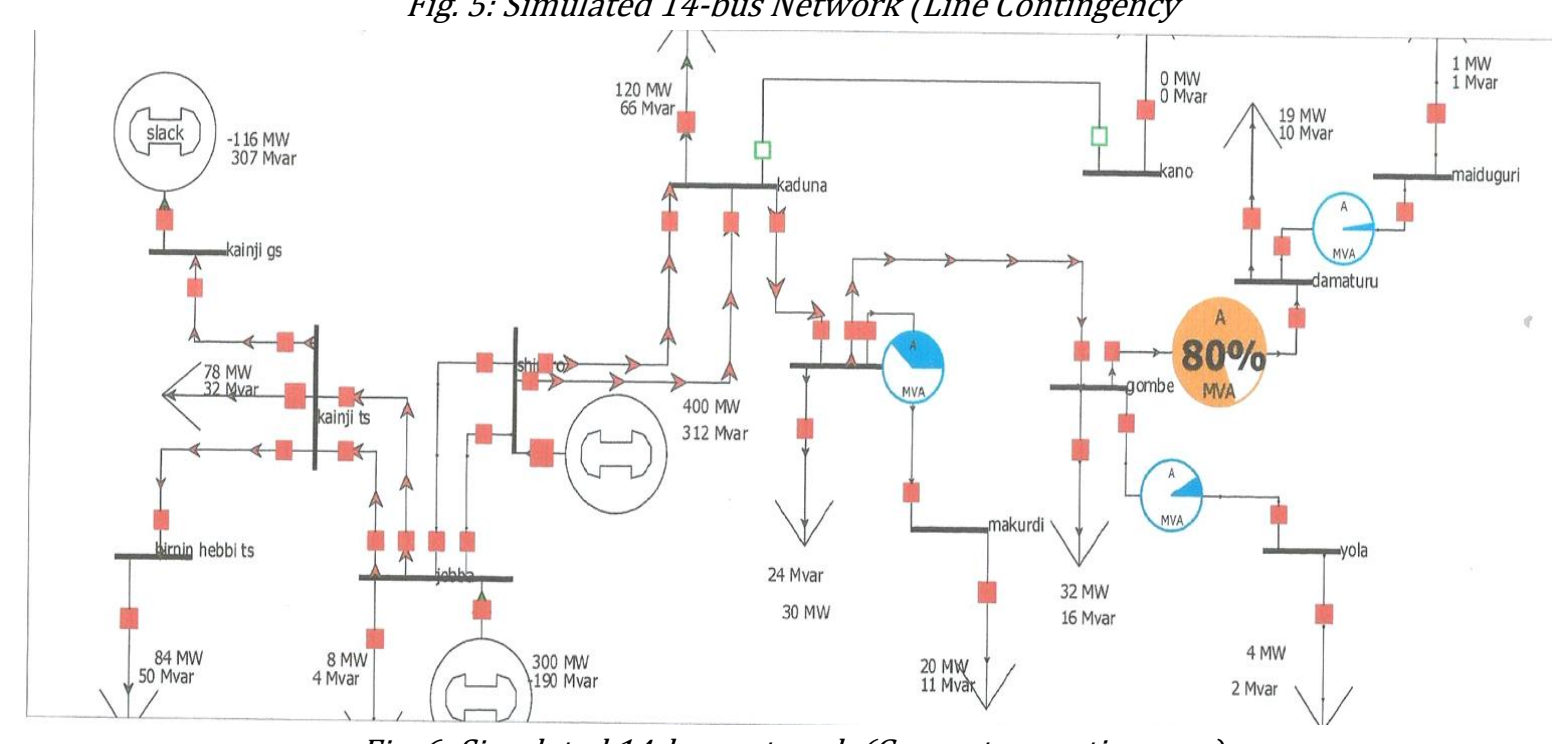

Fig. 6: Simulated 14-bus network (Generator contingency)

Table 3: Comparison of ATC values obtained under normal condition and under contingencies (line and generator contingency in $N$ - $R$ algorithm

\begin{tabular}{llllll}
\hline S/N & From bus & To bus & $\begin{array}{l}\text { ATC(MW)/ } \\
\text { Normal }\end{array}$ & $\begin{array}{l}\text { ATC (mw) line } \\
\text { contingency }\end{array}$ & $\begin{array}{l}\text { ATC(MW) generator } \\
\text { contingency }\end{array}$ \\
\hline 1. & Kainji GS & Kainji TS & -243.94 & 176.33 & -597.34 \\
2. & Kainji TS & Birnin/kebbi TS & -33.09 & -33.08 & -33.18 \\
3. & Kainji TS & Jebba TS & -10.93 & 409.57 & -356.73 \\
4. & Jebba TS & Shiroro & -299.46 & 130.87 & -316.41 \\
5. & Shiroro & Kaduna & -618.97 & -269.06 & -618.92 \\
6. & Kaduna & Kano & -251.77 & 0 & -251.74 \\
7. & Kaduna & Jos & -68.34 & -93.58 & -68.34 \\
8. & Jos & Gombe & -51.95 & -70.34 & -51.95 \\
9. & Jos & Makurdi & 40.93 & 40.21 & 40.93 \\
10. & Gombe & Damaturu & 28.57 & 22.67 & 28.57 \\
11. & Damaturu & Maiduguri & 59.07 & 58.89 & 59.07 \\
12. & Gombe & Yola & 56.14 & 55.53 & 56.14 \\
\hline
\end{tabular}

Table 4 shows the values of minimum active and reactive power that the stations can transfer (i.e. ATC) without experiencing network congestion. The minimum active powers as well as their respective bus voltages are shown in Table 5 (i.e. ATC) without also having network congestion. This in turn can then be sent to other areas where it is required and quantified in monetary terms. 


\section{CONCLUSION}

In this research work, Newton Raphson (N-R) power flow method was used to compute ATC for 3-bus and 14-bus systems. The results obtained using N-R power flow for the 3 bus system was compared to the results of the modeled network in PWS and the difference/error was computed. The difference was observed to be minimal. The essence is to validate the degree of accuracy of the software used for the study. From this research work, the effect of contingencies (sudden disturbance) on ATC of transmission network was determined as well as its simulation time was determined in the study. It was found that when generator/line contingency occurs the ATC of the network reduces.

Table 4: $P-Q$ values at the various buses

\begin{tabular}{lcc}
\hline Bus Name & $\mathrm{P}(\mathrm{MW})(\mathrm{min})$ & $\mathrm{Q}(\mathrm{MVAR})(\mathrm{min})$ \\
\hline Kainji G.S & 657.4 & -198.2 \\
Kainji T.S & 78 & 32 \\
B/Kebbi TS & 84 & 50 \\
Jabba GS & 0 & 0 \\
Jabba TS & 7.6 & 3.8 \\
Kaduna TS & 120 & 66 \\
Shiroro & 400 & 1032 \\
Jos TS & 28.6 & 22.9 \\
Gombe TS & 27.5 & 14.1 \\
Makurdi TS & 19 & 10.5 \\
Damaturu TS & 16.2 & 8.2 \\
Kano TS & 198.2 & 87.2 \\
Maiduguri Ts & 0.9 & 0.4 \\
Yola TS & 3.8 & 1.9 \\
\hline
\end{tabular}

Table 5: $P-V$ values at the various buses

\begin{tabular}{lcc}
\hline Bus Name & $\mathrm{P}(\mathrm{min})$ & Voltage(PU) \\
\hline Kainji G.S & 657.4 & 1 \\
Kainji T.S & 78 & 0.9914 \\
B/Kebbi TS & 84 & 0.9046 \\
Jabba GS & 0 & 0 \\
Jabba TS & 7.6 & 0.9826 \\
Kaduna TS & 120 & 0.8677 \\
Shiroro & 400 & 1 \\
Jos TS & 28.6 & 0.6030 \\
Gombe TS & 27.5 & 0.3017 \\
Makurdi TS & 19 & 0.6020 \\
Damaturu TS & 16.2 & 0.1425 \\
Kano TS & 198.2 & 0.4894 \\
Maiduguri Ts & 0.9 & 0.1347 \\
Yola TS & 3.8 & 0.2966 \\
\hline
\end{tabular}

It has also established how to accurately and easily pick the transmission lines that are congested and deal with those congestion either by redistributing the excess power being transferred, allocating the congestion changes on the source and sink Pair responsible for the congestion or even opening such a line completely. ATC plays an important role in bi-lateral energy market. It indicates the amount of extra power that can be transferred on a transmission network between two interconnected buses or areas. This work did not just show methods of computing ATC but also showed how this computation can be useful in congestion management, transmission pricing and transmission reservation.

\section{RECOMMENDATION}

In the current deregulated environment, players in the electricity market can consume energy in huge amounts, forcing transmission lines to be operated beyond their capacities resulting in congestion. Congestion can lead to increase in market price and may become hindrance to the open electricity trade in the current deregulated market. It is recommended that for effective power system planning, security enhancement, power reservation in energy market applications, it is safe to say that computation of ATC is essential.

\section{REFERENCES}

[1] Babulai C. K and Kannan P. S. "A Novel Approach for ATC computation in Deregulated Environment", Journal of Electrical System, Vol. 2, Number 3, pp. $146-149,2006$.

[2] H. S. Labo. "Current status and future outlook of the transmission network," in Investors' Forum for the Privatization of PHCN Successor Companies, Abuja Nigeria, January 18,.pp 6-8, 2010.

[3] Potturi, K and Nireckshana T. "ATC Enhancement with load models - A Comprehensive Evaluation using FACTS", Int. J. of Innovative Research in Advanced Engineering Vol.2, Issue 2, , pp 28 - 31, 2015.

[4] Omorogiuwa, E and Ekiyor M. T. "Exploring Technically Feasible and Economically Viable Hybrid Renewable Energy Solution for Off-Grid Electricity Supply" American Journal of Engineering Research (AJER), Volume-6, Issue-7, ,pp-92-105, 2017.

[5] Mohammed, S., Hatim, Y and Zuyi L. Market Operations in Electric Systems, Forecasting and Risk Management, Wiley-Interscience, New York, 2002.

[6] Sophia, J. G and Vijaya K. P. "Congestion Management in Competitive Power Market using TCSC", ARPN Journal of Engineering and Applied Science, Vol.10, Number.9, pp. 4271 - 4273, 2015.

[7] Swapna, G., Rinivasrao J. S., and Amaranth J. "Sensitivity Approach to Improve Transfer 
Capability through Optimal Placement of TCSC and SVCs", International Journal of Advances in Engineering and Technology, Vol.4, Issue 1, pp. 525 - 536, 2012.

[8] Padhy, N., "Solutions to Unit Commitment Problem Using Hybrid Models and a Comparative Study of Expert System, Fuzzy System and Genetic Algorithm", International Journal of Electric Power and Energy System, Vol.-23, No.-8, November, pp 827-836, 2001.

[9] Ejebe, G. C., Tong, J and Waight, J. G. l. "Available Transfer Capability Calculations", IEEE Transactions on Power Systems, Vol. 13, Number 4, pp. 1521-6, 1998.

[10] Ventateswarlu, $\mathrm{K}$ and Saibabu C. H. "Enhancement of Available Transfer capability in de-regulated power system by optimal of TCSC and SVC using RGA", Int. J. of Emerging Technology and Advance Engineering, Vol.2 Issue 7, 2012, pp. $85-88$.

[11] Saadat H. Power System Analysis, Tata McGrawHill companies Inc. New Delhi pp.189 - 240, 2002.

[12] Vara, P.J and Suresh B.D, "Point of collapse constrain ATC enhancement with TCSC", International Journal of Recent Trends in Engineering and Technology, Vol. 4, Number 3, pp.81 - 84, 2010.

[13] Gupta J. B. A course in Power System, kataria S. K and Sons, 2013, pp.451 - 456.

[14] Chandrasekar, K and Rsmana N. V, "A fast computational techniques to Assess total transfer capability using brodon- Shamanski", Global J. of researches in Engineering, Vol.11 Issue 5, 2011, pp. 13 - 15, 2011.

[15] Mojgan, H., Mohammadsoroush, S and Mahdi, H. "Available transfer capability and least square method", Scientific Research and Essays, Vol.7 Number 18, pp. 1777 - 1785, 2012, 2012.
[16] Naresk, Y. and Prashant, S. "Available transfer capability using DCPTDF incorporating multiple line contingences and generator addition under deregulated environment", Int. J. of Advanced Research in Electrical, Electronics and Instrumentation Engineering Vol.2, Issue 6, pp. 2297 - 2300, 2013.

[17] Bongkoj,S." The Transfer Capability: Terms, Definitions, Calculations and Applications". $K K U$ Engineering Journal, Vol.3 Issue 39, pp. 311 - 314, 2012.

[18] Gupta S.K and Richa B. "ATC in Competitive Electric Market using TCSC", Int. Journal of Electrical, Computer, Electronics and Communication Engineering, Vol.8 No.2, pp. 304 307, 2014.

[19] Ahmad, A. S., Mark, N. N., and Agbachi E. O "Available Transfer Capability (ATC) as Index for Transmission Network Performance - A Case Study of Nigerian 330kV Transmission Grid ", International Journal on Electrical Engineering and Informatics - Vol. 6, Number 3, 2014 pp.479486.

[20] Dako, S, Ivan, S., "Evolutionary Algorithm for calculating Available Transfer Capability", Journal of Electrical Engineering, Vol. 64, Number.5, 2013,pp. 291 - 297.

[21] Prathiba, R. Balasingh, M. and Karuppasamypandiyan, M."Optimal Selection and Allocation of Generator for Static ATC using Differential Evolution Algorithm", Int. J. of Engineering and Technology Vol. 6 Number.2, 2014, pp. 948 - 951.

[22] Barasara, N. P and Joshi, A. K "Determination of ATC In Deregulated Power System Using Ac Load Flow Method", Journal of Information, Knowledge And Research In Electrical Engineering Volume 02, Issue - 02 Page 367.

Appendix 1: Bus data of a 330kv 14-Bus network

\begin{tabular}{|c|c|c|c|c|c|c|c|c|}
\hline \multirow{2}{*}{$\mathrm{S} / \mathrm{N}$} & \multirow{2}{*}{ Bus Name } & \multicolumn{2}{|c|}{ Generator } & \multicolumn{2}{|c|}{ Load } & \multirow{2}{*}{ Voltage (pu) } & \multirow{2}{*}{ Angle (Degre) } & \multirow{2}{*}{ Bus Type } \\
\hline & & $\mathrm{P}$ & $Q$ & $\mathrm{P}$ & $\mathrm{Q}$ & & & \\
\hline 1. & Kainji G.S & - & - & 0 & 0 & 1 & 0 & Slack \\
\hline 2. & Kainji TS & - & - & 78 & 32 & 1 & 0 & $P Q$ \\
\hline 3. & B/Kebbi & - & - & 84 & 50 & 1 & 0 & $P Q$ \\
\hline 4. & Jebba G.S. & 300 & 125 & - & - & 1 & 0 & PV \\
\hline 5. & Jebba TS & - & - & 7.64 & 3.79 & 1 & 0 & $P Q$ \\
\hline 6. & Kaduna & - & - & 120 & 66 & 1 & 0 & $P Q$ \\
\hline 7. & Shiroro & 400 & 180 & - & - & 1 & - & PV \\
\hline 8. & Jos TS & - & - & 30 & 24 & 1 & 0 & $P Q$ \\
\hline 9. & Gombe TS & - & - & 70 & 36 & 1 & 0 & $P Q$ \\
\hline 10. & Makurdi & - & - & 20 & 11 & 1 & 0 & $P Q$ \\
\hline 11. & Damaturu & - & - & 164 & 83 & 1 & 0 & $P Q$ \\
\hline 12. & Kano TS & - & - & 250 & 110 & 1 & 0 & $P Q$ \\
\hline 13. & Maiduguri & - & - & 10 & 5 & 1 & 0 & $P Q$ \\
\hline 14 & Yola T.S & - & - & 10 & 5 & 1 & 0 & $P Q$ \\
\hline
\end{tabular}


Determination of Atc in Competitive Electricity Market using Nigerian 3-Bus and 14-Bus ..., E. Omorogiuwa \& E. Harrisson

Appendix 2: Line data of a 330kv 14-bus network

\begin{tabular}{lllccc}
\hline S/N & From Bus & To Bus & $\mathrm{R}$ & $\mathrm{X}$ & $\mathrm{Y}$ \\
\hline 1. & Kainji G.S & BininKebbi & 0.0786 & 0.0246 & 0.305 \\
2. & Kainji TS & Jebba TS & 0.0205 & 0.246 & 0.308 \\
3. & Kainji GS & Kainji TS & 0.002 & 0.022 & 0.033 \\
4. & Jebba TS & Shiroro & 0.062 & 0.0702 & 0.927 \\
5. & Shiroro & Kaduna TS & 000249 & 0.0292 & 0.364 \\
6. & Kaduna TS & Kano & 0.058 & 0.0699 & 0.874 \\
7. & Kaduna TS & Jos & 0.049 & 0.599 & 0.927 \\
8. & Jos & Makurdi & 0.002 & 0.0022 & 0.308 \\
9. & Jos & Gombe & 0.786 & 0.0942 & 1.01 \\
10. & Gombe & Damaturu & 0.0785 & 0.0942 & 1.178 \\
11. & Damaturu & Maiduguri & 0.0756 & 0.0842 & 1.178 \\
12. & Gombe & Yola & 0.0245 & 0.0292 & 1.01 \\
\hline
\end{tabular}

Source: Transmission Company of Nigeria Oshogbo 